\title{
Power distribution system fault monitoring device for supply networks in Nigeria
}

\author{
Olalekan Kabiru Kareem ${ }^{1}$, Aderibigbe Israel Adekitan ${ }^{2}$, Ayokunle Awelewa ${ }^{3}$ \\ ${ }^{1}$ Department of Electrical and Electronic Engineering, University of Ibadan, Nigeria \\ ${ }^{2,3}$ Department of Electrical and Information Engineering, Covenant University, Nigeria
}

\begin{abstract}
Article Info
Article history:

Received Jul 14, 2018

Revised Dec 18, 2018

Accepted Jan 10, 2019

\section{Keywords:}

Energy supply reliability Fault detection

Power distribution network Power system protection System monitoring

ABSTRACT

Electric power is the bedrock of our modern way of life. In Nigeria, power supply availability, sufficiency and reliability are major operational challenges. At the generation and transmission level, effort is made to ensure status monitoring and fault detection on the power network, but at the distribution level, particularly within domestic consumer communities there are no fault monitoring and detection devices except for HRC fuses at the feeder pillar. Unfortunately, these fuses are sometimes replaced by a copper wire bridge at some locations rendering the system unprotected and creating a great potential for transformer destruction on overload. This study is focused on designing an on-site power system monitoring device to be deployed on selected household entry power cables for detecting and indicating when phase off, low voltage, high voltage, over current, and blown fuse occurs on the building's incomer line. The fault indication will help in reducing troubleshooting time and also ensure quick service restoration. After design implementation, the test result confirms design accuracy, device functionality and suitability as a low-cost solution to power supply system fault monitoring within local communities.
\end{abstract}

Copyright (C) 2019 Institute of Advanced Engineering and Science. All rights reserved.

Corresponding Author:

Aderibigbe Israel Adekitan,

Department of Electrical and Information Engineering,

Covenant University,

Km 10, Ota, Ogun State, Nigeria.

Email: ade_kitan@yahoo.com

\section{INTRODUCTION}

Adequate power supply is a major challenge in Nigeria; the most populous country in Africa due to insufficient energy generation [1,2]. The peak power that was generated on August 31, 2018 stood at $4341 \mathrm{MW}$ [3], and this is just about a fraction of the estimated national energy requirement of 31,000 MW, with an expected $10 \%$ yearly increase [4]. Alternative energy sources such as waste to energy, wind energy and solar energy need to be developed to support the current power generation [5-7]. Ensuring every customer gets a reasonable share of the meagre energy is a daunting task which is achieved via load shedding and power outages [8]. Frequent switching on and off, of power supply creates line stability issues which also induces line faults [9].

A power supply system consists of generation, transmission, distribution and utilization of electric power. Power supply networks are prone to operational faults like short circuits, line to line faults, floating neutral issues, overloading, line voltage fluctuations, lightning strikes etc. [10-12]. Power stability and quality issues affect the operation and efficiency of equipment e.g. in induction motors, voltage unbalance creates imbalance currents which results in torque and power pulsations [13-16]. Preventing excessive damage when these faults occur requires the installation of line protective devices. In Nigeria, some effort has been made by deploying protection systems and monitoring scheme in the operation, protection and 
control of the power generation and transmission system which still need significant improvement [17, 18], but relatively, almost no attention is given to distribution system monitoring.

When there is a fault on a section of the distribution network resulting in power outage, the energy consumers are subjected to avoidable, prolonged blackout due to the time it takes the consumers to report at the nearest power Distribution Company (DISCO) office, and the time it takes for the station to respond and mobilize to the faults zone which may take days and even longer in some cases, and this is further aggravated by the time it takes the technical team to troubleshoot, identify and implement necessary corrections, especially when expensive faulty components need to be replaced. Inadequate energy generation coupled with supply faults has forced a great percentage of the population to depend on alternative energy sources like diesel and petrol generators which increases energy cost and the production of greenhouse gases.

In desperation, when a fault occurs on the distribution network, particulary when only a section of customers are affected, and the affected customers can see the homes of unaffected customers lighted up; some consumers have resulted to engaging the services of unqualified people such as road-side electricians to fix the faults. This usually causes more danger to the system due to inexperience, and this may result in transformer damage.

This study is focused on developing a model fault monitoring device that will detect specific fault(s) on the $415 \mathrm{~V}$ distribution network at the household entry lines and also give a visual indication of the nature of the fault thereby serving as a guide for customers when reporting faults. The device also serves as a tool for fast fault identification by DISCO officials toward ensuring prompt repair, minimum supply downtime and improved service quality to consumers.

\section{ELECTRIC POWER SYSTEMS IN NIGERIA}

Electric power system encompasses power generation, transmission, distribution and utilization of electric power. There are two main sources of energy for electric power generation which are fossil fuels and non-fossil fuels.

a. Fossil fuels are coals, lignite, petroleum and natural gas.

b. Non-fossil fuels are hydro, wind, tidal, solar, solar thermal, nuclear fission and fusion.

The main components of an Electric Power System are:

a. Generators

b. Transformers (Power Transformer, Current Transformer and Potential Transformer)

c. Lines (Transmission and Distribution Lines)

d. Switchgear (Circuit Breaker, Relays, Bus bars, Disconnect Switch etc.)

e. Other components include Lightning arrester, Insulator etc.

There are several electric power generating plants in Nigeria. These stations include the Egbin Thermal Station (Thermal Plants), Shiroro, Kainji, and Jebba (Hydro-Power Plants), Omotosho and Papalantoro (Gas Plants) etc [19]. As shown in Figure 1 and Figure 2, power is generated at the power generating station at a voltage level of $6.6-25 \mathrm{kV}$, this is stepped up to $330 \mathrm{kV}$ for transmission via dedicated $330 \mathrm{kV}$ lines to the national grid. The electric power is then transported from the grid network to the load centres via the $330 \mathrm{kV}$ and $132 \mathrm{kV}$ lines. At the sub transmission level the voltage is stepped down to $33 \mathrm{kV}$ by $132 \mathrm{kV} / 33 \mathrm{kV}$ transformer which supplies the Injection Sub-stations or Distribution Sub-stations on 33kV lines. At the Distribution Sub-stations the $33 \mathrm{kV}$ is stepped down to $11 \mathrm{kV}$ to feed $11 \mathrm{kV}$ feeder lines which facilitate the supply of electric power to the residential, commercial and industrial consumers. Primary customers are supplied at $11 \mathrm{kV}$ while secondary customers receive power via $11 \mathrm{kV} / 415 \mathrm{~V}$ distribution transformers. However, there are $33 / 0.415 \mathrm{kV}$ transformers used as distribution transformers at some locations. The secondary customers receive three-phase power at $50 \mathrm{~Hz}, 415 \mathrm{~V}$ for the industrial loads and $220 \mathrm{~V}$ single-phase for residential loads. 


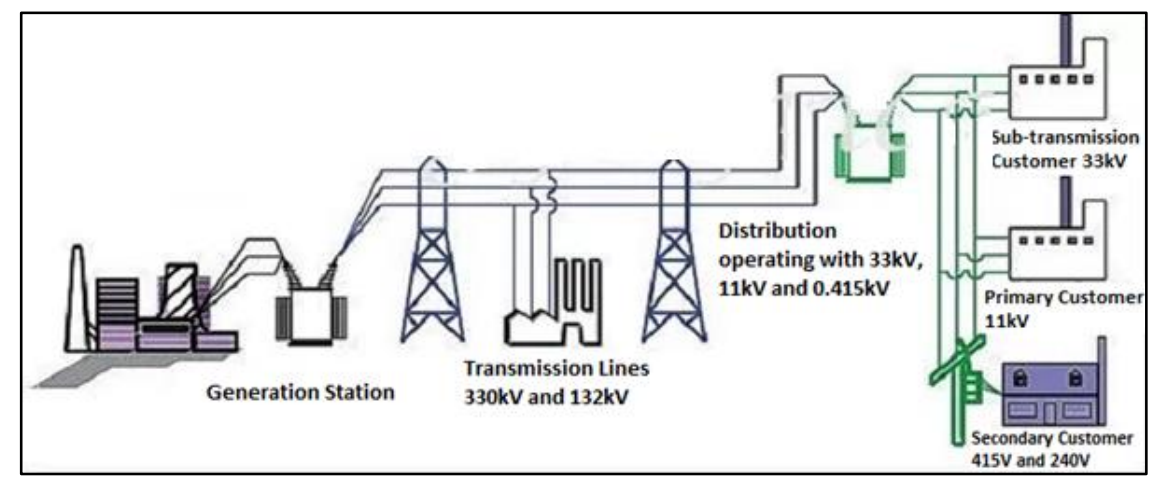

Figure 1. Power supply network in Nigeria [20]

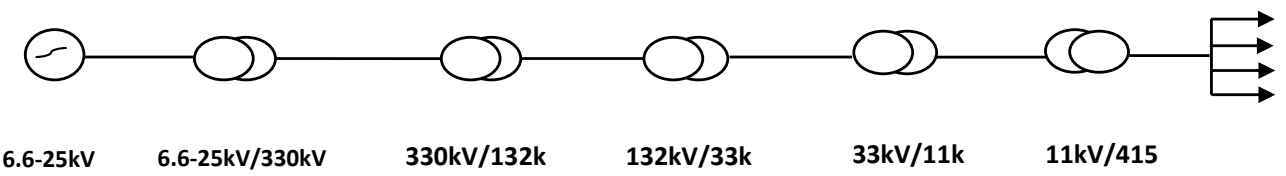

Figure 2. Line diagram of voltage generation, transmission, and distribution in Nigeria

\section{POWER SYSTEM PROTECTION}

In a power system, fault can develop in any of the components i.e. generators, buses, transformers and vulnerable transmission lines that are exposed to the environment. Faults can be classified into two categories; open circuit and short circuit faults. These faults can be detected automatically using relays, which activates circuit breakers to isolate the faulty section of the transmission line. The combination of circuit breakers, relays and the appropriate relay coordination schemes using the traditional bus protection or artificial intelligence and expert systems [21-25] forms a protective system which may also incorporate automatic fault diagnosis and identification [26-29]. Protective devices and relays should be well coordinated to act fast and accurately to minimize damages when fault occurs [25, 30].

Protective systems help to minimize power system damage and reduce the cost of repair. It safeguards the total power system, guarantees continuity of supply and ensures the safety of personnel from hazardous voltages. Protective systems ensure maximum profit on the huge capital outlay on power supply network and equipment, and it also ensure that consumers get reliable service. The responsibility of ensuring adequate system protection is managed by the Protection, Control and Metering (PC\&M) department of the Power Distribution Company in Nigeria. Due to economic challenges and the level of technological development, protection systems are mostly of the traditional relay bus protection type, with basic or no form of artificial intelligence or expert system implementation. There are various levels of protection on the supply network, as discussed below.

\subsection{Protection scheme at the generation level}

(a) Generator phase to phase winding protection (differential relay)

(b) Anti-motoring protection (reverse or directional relay)

(c) Over-excitation protection (directional or reverse-power relay)

(d) Phase-overvoltage protection (overvoltage relay)

(e) Safeguard against current supply or field voltage loss (offset mho relay).

\subsection{Protection scheme at the transmission level}

Transmission lines are spread over a significant geographic area, and as a result, they are exposed to variety of hazards. Typical causes of line faults include lightning, wind, ice, snow salt spray, birds, airplanes, automobiles and man. The line fault could be line to ground, line to line or earth (leakage) faults. Power lines experience more faults than any other components of the system. The protection devices include:

(a) Distance relay protection

(b) Over current relay protection

(c) Earth fault relay protection

(d) Standby earth fault protection

(e) Restricted earth fault relay.

Power distribution system fault monitoring device for supply networks in Nigeria (Olalekan Kabiru Kareem) 


\subsection{Power transformer protection}

Transformers are the most expensive and critical power system component [12], and it requires utmost protection $[30,31]$ to ensure longevity. Transformer failure may result in a lengthy and costly power outage. Transformer protection usually takes the following form:

a. Differential relay protection offers the best form of protection for both ground and phase faults,

b. Restricted earth fault protection scheme in which the protective relay operates to trip the primary and secondary transformer breaker but not the line breaker,

c. Over current and earth fault protection which comprises two over current relay and one earth fault relay,

d. Thermal relay protection which responds to the copper winding's temperature increase due to increase in load, causing the auxiliary cooling system (fan or pump) to operate, and

e. Buchholz protection in which the protective relay operates in response to sudden pressure rise and gas development, internal arcing faults, and slow decomposition of insulating materials.

\subsection{Protection scheme at the distribution level}

The $11 \mathrm{kV}$ feeder line is usually protected by a protective relay in the control room of the Distribution Sub-Station (DSS) but at the customer end, there is no form of status monitoring and often the only means of protection between the $11 \mathrm{kV}$ feeder lines and the utility network at the high voltage end is the J\&P Fuse installed on the three phases at the primary side of the distribution transformer while a High Rupturing Capacity (HRC) fuse is installed between the $415 \mathrm{~V}$ feeder pillars and the load, at the transformer secondary side. Unfortunately, the HRC fuses in Figure 3, after snapping on fault current detection are sometimes replaced by a copper wire bridge which defeats the protective purpose of a fuse. The power distribution network structure is shown in Figure 4.

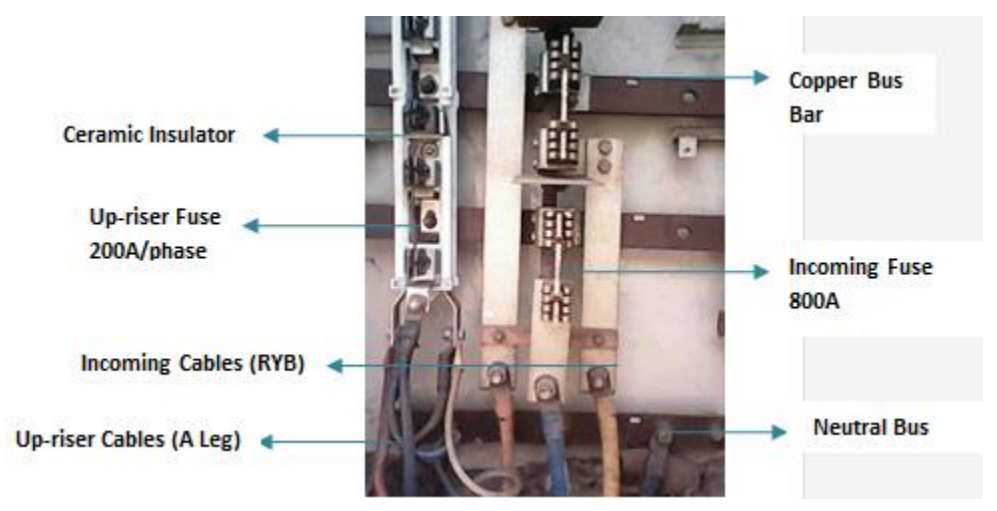

Figure 3. A single unit feeder pillar

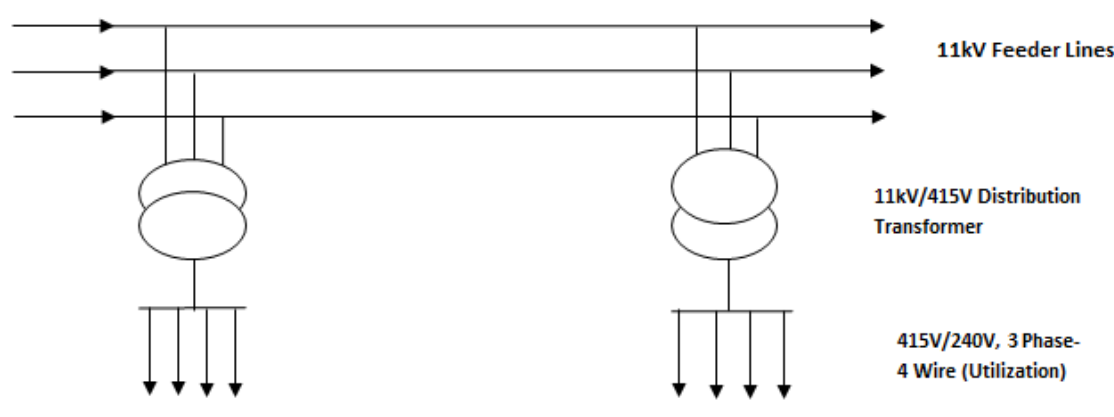

Figure 4. Electric power network at utilization level

In an attempt to address the lack of adequate power monitoring system in the Nigerian power supply network, the study by [32] proposed a GSM based power system monitoring device that tracks the current, voltage, and the frequency of the supply of the transmission network. When a fault is detected a message is sent via SMS to the utility centre. The study by [33] implemented a sub-station fault monitoring device that creates a log of all the faults detected, and also sends a message to the Distribution Control Centre when a fault is detected. 


\section{DESIGN OF A HOUSEHOLD ENTRY LINE POWER SUPPLY MONITORING DEVICE}

The design analysis of the implemented, model household-based, power-inlet line status monitoring system is discussed in this section. The block diagram of the setup is shown in Figure 5. The device is powered by a $12 \mathrm{~V}-0 \mathrm{~V}-12 \mathrm{~V}$ rectified and regulated DC power supply with a battery backup connection to ensure continuous status monitoring when power supply fails, and also to enable the indication of no voltage situation (phase off).

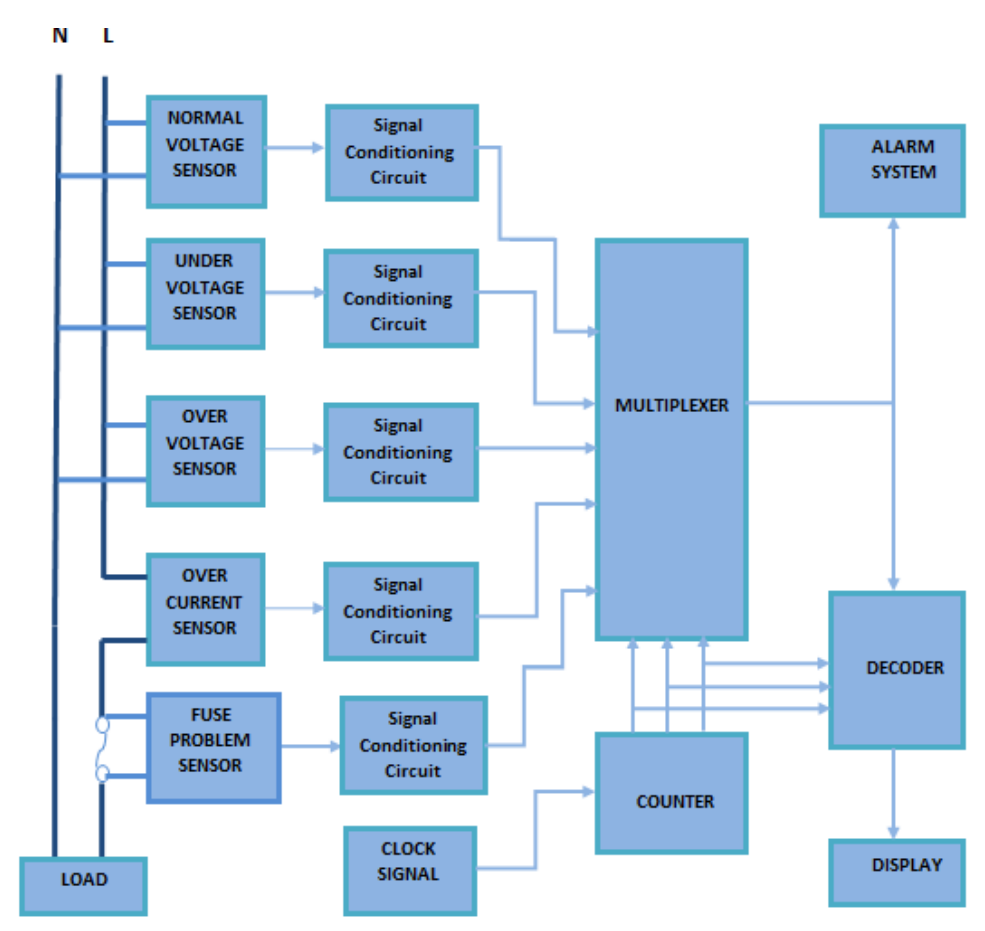

Figure 5. Block diagram of the electronic monitoring device

\subsection{Over voltage, under voltage and normal voltage detection}

In Nigeria, at the consumer end of the supply, the rated single-phase voltage is $220 \mathrm{~V}$ but due to various line conditions and loading, the actual voltage varies from the rated value. In this design, based on the common voltage supply range of automatic voltager stabilizers in Nigeria [34], 250V and above is taken as high voltage, and $180 \mathrm{~V}$ and below as low voltage. It follows that any voltage in-between the high and low voltage is considered acceptable. The voltage is sensed by a potential transformer.

As shown in Figure 6, a basic potential transformer has two capacitors connected in series for sharing the line voltage, with an inductor connected in the transformer primary for tuning the circuit to the line frequency, and a transformer for stepping down the voltage for instrumentation purposes. In real practice, multiple capacitors are connected in series to ensure proper voltage sharing and a low voltage drop across the final capacitor.

For this study the potential transformer has a turns ratio of $k=\frac{1}{10}$ such that

$$
V_{2}=k V_{1}
$$

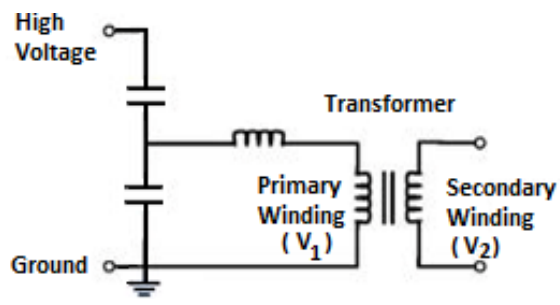

Figure 6. A simple potential transformer (PT) 
The transformed voltage is rectified to dc output Vo. This voltage is conditioned by the signal conditioning unit, comprising two operational amplifiers (op-amp) U16 and U17 configured as comparators as shown in Figure 7(a). The op-amp used is LM 358. A potential divider of R3 and R4 is used to generate the reference voltage Vref for the under voltage and over voltage operational amplifiers. This value is calculated as follows:

$$
V_{\text {in }}=\frac{R_{3}}{R_{3}+R_{4}} \times V_{o}
$$

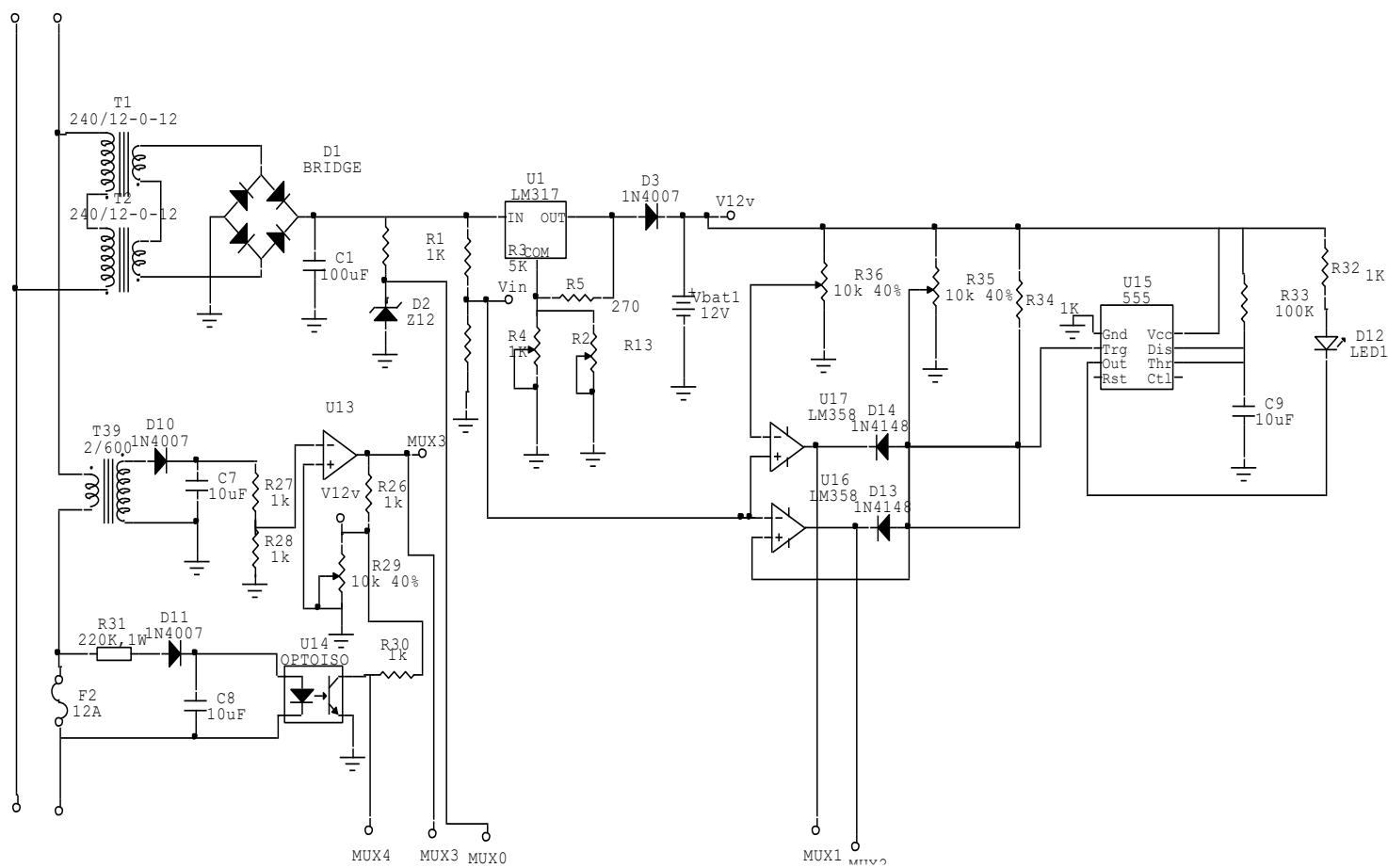

Figure 7. Schematic diagram of the electronic monitoring device (Part A)

At the onset of high Voltage $(250 \mathrm{~V}), \mathrm{V}_{2}=25 \mathrm{~V}$ and for the U3 op-amp Vref $=4.17 \mathrm{~V}$ while at the onset of low voltage $\mathrm{V}_{1}=18 \mathrm{~V}$, therefore for the $\mathrm{U} 2$ op-amp Vref $=3.0 \mathrm{~V}$. The output of the op-amps is connected to the corresponding input terminals of the multiplexer MC14051B via an inverting IC, MC14049B.

For the normal voltage situation, the under voltage and the over voltage comparators are connected as window comparator mode with Diode-Resistor Logic (DRL) AND Gate and 12V supply. Now, at other voltage values in-between the reference values analysed above, which is taken as normal voltage range, none of the comparators will toggle, i.e. go low and therefore, there is a trigger input at the 555 timer IC (active LOW output) connected in one shot mode via R8. This produces a low digital output (pulse) and the normal voltage LED indicator is turned on. The width of the output pulse is:

$$
\begin{aligned}
& t_{w}=1.1 R C \\
& t_{w}=1.1 \times 100 \mathrm{k} \Omega \times 10 \mu=1.1 \mathrm{~s}
\end{aligned}
$$

\subsection{No voltage conditions}

The no voltage (phase off) condition is when there is no voltage at the mains. This is detected by using the zener diode D2 (Z12) of $12 \mathrm{~V}$ (i.e. Vz). It should be noted that at this situation, the backup battery powers the entire circuitry. When there is voltage supply Vo from the rectifier output, D2 acts as a normal zener diode and this voltage is given a drop by R1 thereby giving a logic 1 on MC14049. At phase off, there is no voltage at the rectifier output and the battery supply is isolated from D2 by diode D3, and therefore $\mathrm{Vz}$ enables a logic zero on the MC14049 IC, generating logic 1 on the input of the multiplexer. 


\subsection{Over current sensing unit}

The over current sensing is achieved by the use of a current transformer connected in series with the mains. Current Transformers (CT) are applied in power systems to measure the current flowing through the network. This is necessary because the current is too high to be directly measured by instruments. A value of the load current in the primary winding is taken as the threshold value; at this point a corresponding voltage is induced at the secondary of the current transformer. This voltage is used in the signal conditioning to detect current above the threshold value. The threshold current, voltage equivalent is used to pre-set the Vref of U5 using 10K variable resistor.

\subsection{Fuse problem sensing circuit}

The circuit consists of an opto-isolator U12, 220K, $1 \mathrm{~W}$ power resistor R24, diode D9 and filter capacitor $\mathrm{C} 5$. When the current above the fuse rating is being drawn, the fuse snaps, thereby causing a phase voltage Vph across the circuit R24, D9 and C5. If the mains voltage is Vph, the current required to turn the internal LED on is calculated as:

$$
I=\frac{V_{p h}-V_{D}}{R_{24}}
$$

where $\mathrm{V}_{\mathrm{D}}$ is the diode voltage drop.

\subsection{The processing stage}

The processing stage consists of the clock signal, counter, and the multiplexer. The clock signal is generated using a 555 timer IC which is connected in astable mode, using external resistors R14 and R15 (variable) with capacitor C4. Also included in the design, is the green light LED as the clock output indicator light. The output of the clock is connected to the enable of the counter. The clock frequency is obtained as follows:

$$
f=\frac{1.44}{\left(R_{14}+2 R_{15}\right) C 4}(H z)
$$

The counter used is a CMOS integrated circuit MC14518, 16-pin dual BCD counter with supply voltage range of $3.0 \mathrm{Vdc}$ to $18 \mathrm{Vdc}$ and it has diode protection at all inputs. The multiplexer used is a 16-pin CMOS MC14051 multiplexer with triple diode protection on control inputs as shown in Figure 8.

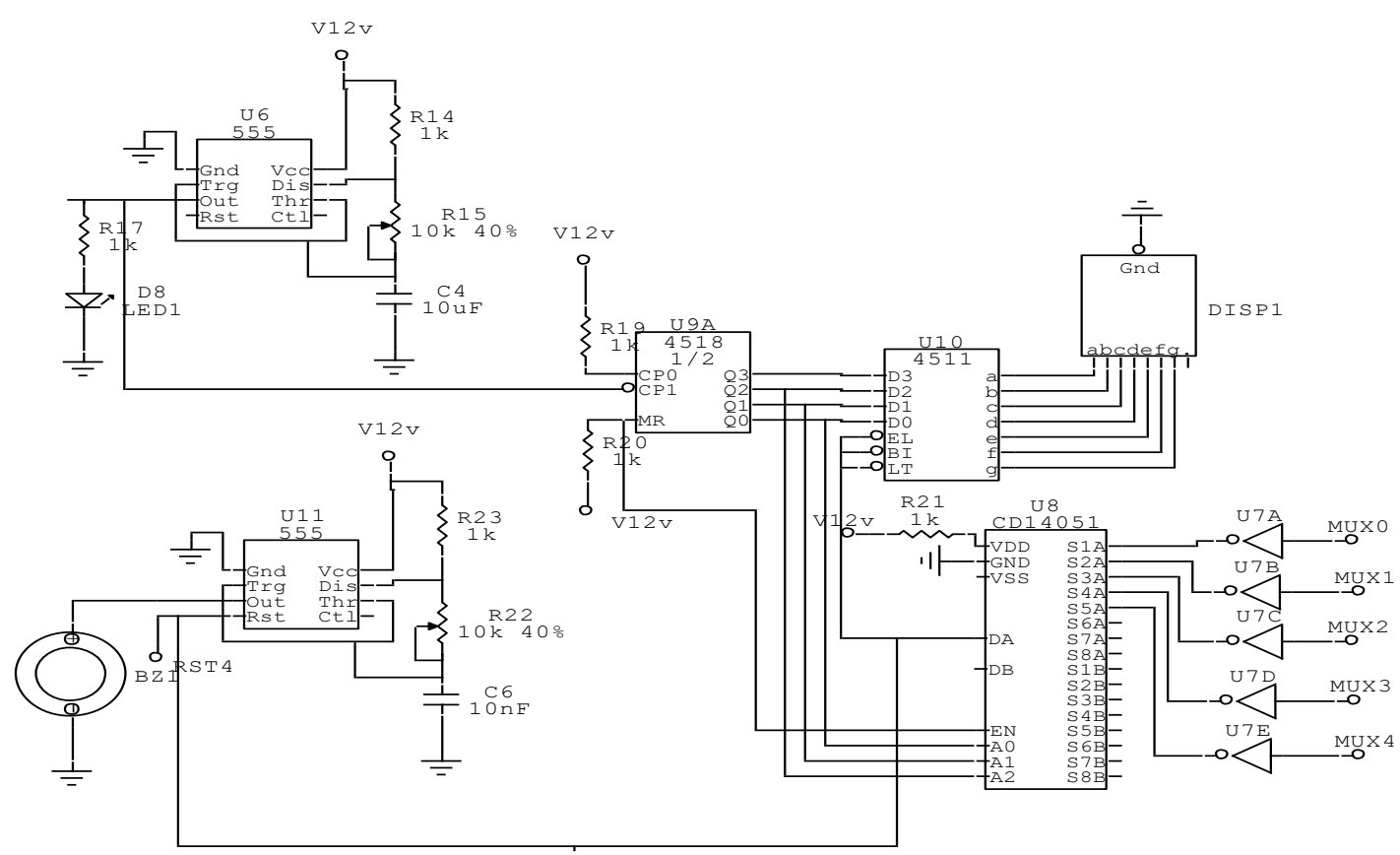

Figure 8. Schematic diagram of the electronic monitoring device (Part B) 


\subsection{The output stage}

As shown in Figure 8, the audible alarm circuit is designed using a 555 timer IC (U11) in astable mode, $10 \mathrm{~K}$ variable resistor $\mathrm{R} 22,1 \mathrm{~K}$ resistor $\mathrm{R} 23,10 \mathrm{nF}$ capacitor $\mathrm{C} 6$, and a buzzer BZ1 with operating voltage range of 3 to $24 \mathrm{~V}$. The frequency of the audible sound can be varied from $13.1 \mathrm{KHz}$ to $144 \mathrm{KHz}$. The output stage comprises the 16-pin BCD-to-7-Segment MC14511 decoder, a common cathode 7-segment display and the alarm circuit. The display is a common cathode 7- segment display whose segments are made of LEDs. The segment with red light colour is chosen so that the output can be easily seen during the day. The segments are labelled a-to-g and are connected to the respective output pins of the MC14511 decoder as shown in Figure 9.

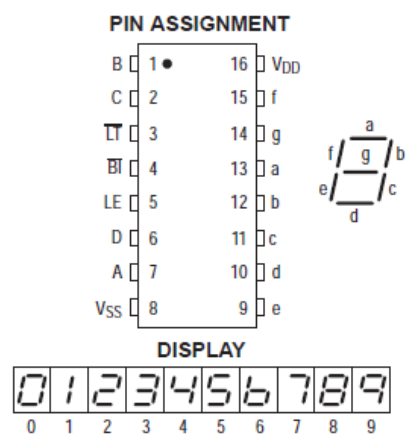

Figure 9. Pin assignment of MC14511 IC decoder and display

\section{RESULTS}

With reference to the design analysis made in section 4 for the circuit diagrams of Figure 7 and Figure 8 , the outputs of the signal conditioning circuits are connected to the inputs of the multiplexer. The status of these inputs determine the number indicated on the 7 segment display based on the condition of the bus, i.e. no voltage (phase off), low voltage, high voltage, over current, and fuse problem. Table 1 shows the assignment of the conditions at the inputs of the multiplexer.

The device is designed to be installed on the entry line into a household to indicate any power supply system fault that occurs on the distribution lines where the household power is sourced, thereby providing visual and audible warnings to the house occupants any time there is a fault on the pole supported power distribution lines. This will enable the house occupant to be aware of the fault development as a result of the audible alarm and fault indication on the LCD, and therefore the household occupant can then contact the power distribution company with detailed information of the house location, and the nature of the fault indicated by the device.

Table 1. Bus conditions and the number indicated on the 7 segment display

\begin{tabular}{cccc}
\hline Bus Condition & $\begin{array}{c}\text { Multiplexer Input } \\
\text { (Input Pin/Select Value) }\end{array}$ & $\begin{array}{c}\text { Number Indicated on the } 7 \\
\text { Segment Display }\end{array}$ \\
\hline Phase off (No Voltage) & X0 & 000 & 0 \\
Low Voltage & X1 & 001 & 1 \\
High Voltage & X2 & 010 & 2 \\
Over Current & X3 & 011 & 3 \\
Fuse Problem (Open Circuit) & X4 & 100 & 4 \\
\hline
\end{tabular}

The five fault conditions were tested during the implementation, and the indication of the display corresponded accurately with the fault condition confirming the functionality of the device. The short circuit condition was tested by injecting a voltage above the pre-set Vref of U5, likewise the blown fuse condition was tested by removing the fuse on the incomer line. The detection of over voltage, under voltage and normal voltage conditions were tested by using a variable voltage supply equipment. The variable potentiometers in the op-amp circuits can be varied to change the reference settings and the point of device activation for each condition. 


\section{CONCLUSION}

This project focussed on designing a device for monitoring fault conditions on the power distribution network within communities by installing the device on the incoming supply lines of a selected building. The design goals were successfully achieved and the test result confirms device functionality and accuracy in detecting and indicating the prevailing power supply fault conditions. This device, coupled with a tag showing the fault condition corresponding with the displayed number on the 7-segment display would enable the energy consumers connected to the supply to give adequate report of fault to the energy company officials which would help the officials to prepare appropriately when reporting for repairs. This brings about easy detection of fault and reduction in down time, as time taken for troubleshooting would be reduced. It would also improve the quality of service provided to the consumers, and ensure improved power availability and use by consumers thereby ensuring uninterrupted flow of revenue for the DISCOs.

\section{RECOMMENDATIONS}

The following are some of the possible improvements to the current design:

a. The design could be microcontroller based. The multiplexer used can be replaced with a microcontroller in order to add some other features to the device. Such features include the use of LCD instead of the 7-segment display to show the status of the supply.

b. The microcontroller-based device could be designed in such a way that when the device detects the abnormal condition, it should disconnect the household loads, in order to prevent them from being damaged.

c. A microcontroller-based device could be incorporated with a suitable communication protocol such as GSM module to report the details of the faults developed using SMS message.

\section{ACKNOWLEDGEMENTS}

The Authors appreciate Covenant University Centre for Research, Innovation and Discovery for supporting the publication of this article.

\section{REFERENCES}

[1] A. I. Adekitan, et al., "Data based investigation of the energy metering type, billing and usage of sampled residents of Ota Community in Nigeria," Data in Brief, vol. 20, pp. 159-172, 2018.

[2] B. B. Adetokun, et al., "Development of an ANN-Based Estimated Electricity Billing System," 2018 IEEE PES/IAS PowerAfrica, pp. 96-101, 2018.

[3] NERC, "Daily Peak Power Generated," 2018. Available: http://nercng.org/index.php/library/industry-statistics/397peak\#graph

[4] C. A. Awosope, "Nigeria Electricity Industry: Issues, Challenges and Solutions," Covenant University 38th Public Lecture, Public Lecture Series, vol. 3, 2014

[5] P. A. Owusu and S. A. Sarkodie, "A review of renewable energy sources, sustainability issues and climate change mitigation," Cogent Engineering, vol. 3, 2016.

[6] S. O. Oyedepo and P. O. Babalola, "Renewable energy technologies in Nigeria: Challenges and opportunities for sustainable development," Renewable Energy Systems, pp. 225-257, 2016.

[7] S. O. Oyedepo, "Towards achieving energy for sustainable development in Nigeria," Renewable and Sustainable Energy Reviews, vol. 34, pp. 255-272, 2014.

[8] A. A. Adewale, et al., "Energy audit and optimal power supply for a commercial building in Nigeria," Cogent Engineering, vol. 5, pp. 1-18, 2018.

[9] I. A. Samuel, et al., "Prediction of voltage collapse in electrical power system networks using a new voltage stability index," International Journal of Applied Engineering Research, vol. 12, pp. 190-199, 2017.

[10] A. E. Lazzaretti, et al., "An integrated monitoring system and automatic data analysis to correlate lightning activity and faults on distribution networks," Electric Power Systems Research, vol. 153, pp. 66-72, 2017.

[11] E. W. Gunther and H. Mebta, "A survey of distribution system power quality-preliminary results," IEEE Transactions on Power Delivery, vol. 10, pp. 322-329, 1995.

[12] K. Karakoulidis, et al., "The temperature measurement in a three-phase power transformer under different conditions," Journal of Engineering Science and Technology Review, vol. 8, pp. 19-23, 2015.

[13] Z. Y. M. Hurtado, et al., "A review on location, detection and fault diagnosis in induction machines," Journal of Engineering Science and Technology Review, vol. 8, pp. 185-189, 2015.

[14] A. Aderibigbe, et al., "The performance of a 3-Phase Induction Machine under Unbalance Voltage Regime," Journal of Engineering Science and Technology Review, vol. 10, pp. 136-143, 2017.

[15] S. A. Kiranmai and A. J. Laxmi, "Hardware for classification of power quality problems in three phase system using Microcontroller," Cogent Engineering, vol. 4, 2017.

[16] A. I. Adekitan, "Supply instability induced torque variations of a three phase asynchronous motor," International Journal of Mechanical Engineering and Technology (IJMET), vol. 9, pp. 572-583, 2018.

Power distribution system fault monitoring device for supply networks in Nigeria (Olalekan Kabiru Kareem) 
[17] I. E. Davidson, et al., "Power System Control Automation in Developing Economies - The Nigerian Experience," IFAC Proceedings Volumes, vol. 33, pp. 93-97, 2000.

[18] A. Abdulkareem, et al., "The use of three-phase fault analysis for rating circuit breakers on Nigeria $330 \mathrm{kV}$ transmission lines," Journal of Engineering and Applied Sciences, vol. 11, pp. 2612-2622, 2016.

[19] Wikipedia, "List of power stations in Nigeria," 2018. Available: https://en.wikipedia.org/wiki/List_of_power_stations_in_Nigeria

[20] e-energyafrica, "Unbundling the Nigerian Power Sector I," 2017. Available: http://e-energyafrica.com/generalcategory/unbundling-the-nigerian-power-sector

[21] Z. Zhu, "The protection of power system based on artificial intelligence," in J. M. Pietraszko and P. Pichappan, Eds., Springer Verlag, vol. 613, pp. 413-422, 2018.

[22] A. A. Bittencourt, et al., "Adaptive Strategies in Power Systems Protection Using Artificial Intelligence Techniques," 15th International Conference on Intelligent System Applications to Power Systems, pp. 1-6, 2009.

[23] R. P. Nath and V. N. Balaji, "Artificial Intelligence in Power Systems," Presented at the National Electronic Conference on Communication and Networking Jeppiaar Engineering College, Chennai.

[24] A. Pathirana, et al., "Development of a hybrid protection scheme for active distribution systems using polarities of current transients," Electric Power Systems Research, vol. 152, pp. 377-389, 2017.

[25] Y. Li, et al., "Intelligent monitoring system design for circuit breaker operating circuit," Dianli Zidonghua Shebei/Electric Power Automation Equipment, vol. 37, pp. 211-217, 2017.

[26] D. Celeita, et al., "Virtual relay design for feeder protection testing with online simulation," 2016 IEEE Industry Applications Society Annual Meeting, pp. 1-7, 2016.

[27] K. P. Wong, "Applications of Artificial Intelligence and Expert Systems in Power Engineering," Expert Systems in Engineering Applications, in S. Tzafestas, Ed., Berlin, Heidelberg: Springer Berlin Heidelberg, pp. 160-178, 1993.

[28] M. Saini, et al., "Algorithm for Fault Location and Classification on Parallel Transmission Line using Wavelet based on Clarke's Transformation," International Journal of Electrical and Computer Engineering (IJECE), vol. 8, pp. 699-710, 2018.

[29] S. Narayana, et al., "Identification of Faults in HVDC System using Wavelet Analysis," International Journal of Electrical and Computer Engineering (IJECE), vol. 2, pp. 175-182, 2011.

[30] E. Ali, et al., "Power transformer differential protection using current and voltage ratios," Electric Power Systems Research, vol. 154, pp. 140-150, 2018.

[31] M. Žarković and Z. Stojković, "Analysis of artificial intelligence expert systems for power transformer condition monitoring and diagnostics," Electric Power Systems Research, vol. 149, pp. 125-136, 2017.

[32] K. O. Okokpujie, et al., "Monitoring and fault detection system for power transmission using GSM technology," 2017.

[33] S. Oyetunji, "Using Substation Automation System for Faults Management and Analysis in Electric Power Distribution Systems in Nigeria," International Journal of Engineering and Technology, vol. 3, 2013.

[34] W. A. Ayara, "An Automatic Mains Voltage Switch Protector for Domestic Appliances," Journal of Emerging Trends in Engineering and Applied Sciences (JETEAS), vol. 5, pp. 56-61, 2014. 